\title{
MARKETING DIGITAL: \\ A INFLUÊNCIA DAS MÍDIAS SOCIAIS DIGITAIS NO PROCESSO DE DECISÃO DE COMPRA DOS CONSUMIDORES DE MEIOS DE HOSPEDAGEM
}

\author{
Leônia Sonalis da Silva Barbosa \\ Graduada em Hotelaria pela Universidade Federal da Paraíba. \\ leoniasonalis@gmail.com \\ Mariana Bueno de Andrade-Matos \\ Professora Doutora do bacharelado em Lazer e Turismo da Escola de Artes, Ciências e Humanidades da \\ Universidade de São Paulo (EACH/USP), São Paulo, Brasil. \\ Doutora em Administração pela Universidade Federal de Pernambuco. \\ buenomariana@usp.br \\ André Riani Costa Perinotto \\ Doutor em Ciências da Comunicação pela Universidade do Vale do Rio dos Sinos, UNISINOS, Rio Grande do Sul, \\ RS., Brasil. \\ Professor Adjunto do Curso de Bacharelado em Turismo da Universidade Federal do Delta do Parnaíba - UFDPar. \\ Professor Permanente do Mestrado em Gestão de Negócios Turísticos da UECE. \\ perinotto@ufpi.edu.br
}

\section{Resumo}

Objetivo do estudo: o presente trabalho teve o objetivo de analisar como consumidores de meios de hospedagem são influenciados por mídias sociais digitais em seus processos de decisão de compra.

Metodologia/abordagem: A pesquisa desenvolvida foi exploratória e quantitativa, utilizando coleta de dados por meio de questionários aplicados online em mídias sociais digitais com consumidores de meios de hospedagem. O questionário foi composto por questões de múltipla escolha e uma questão discursiva. Os dados foram analisados por meio de estatística descritiva e, para a questão discursiva, foi utilizada a análise de conteúdo e, depois, construiu-se uma word cloud (nuvem de palavras).

Originalidade/Relevância: Com a facilidade de acesso à internet que há atualmente, os consumidores estão assumindo papéis mais ativos no processo de decisão de compra, incluindo as suas cinco etapas: reconhecimento do problema, busca de informações, análise de alternativas, decisão de compra e, por fim, o pós-compra. As mídias sociais digitais possibilitam grande diversidade de possibilidades de busca e acesso às informações diversas, o que gera um novo comportamento de compra nos consumidores diante das mudanças que estão ocorrendo na sociedade.

Principais resultados: De acordo com os resultados, os respondentes fazem uso frequente das mídias sociais digitais principalmente para realizarem pesquisas e trocarem informações com outros consumidores, uma vez que as experiências vividas por outros acabam influenciando o processo de decisão de compra de meios de hospedagem.

Contribuições teóricas/metodológicas: Para embasar a discussão, foi desenvolvida uma revisão de literatura a respeito de marketing digital e mídias sociais digitais, comportamento do consumidor online e processo de decisão de compra. Concluiu-se que a etapa mais influenciada pelas mídias sociais é a de busca de informações, na qual os consumidores buscam referências para suas decisões de compra de meios de hospedagem. As mídias sociais mais utilizadas para que esses usuários obtenham informações são o WhatsApp, o Instagram e o Facebook, respectivamente.

Palavras-chave: Redes Sociais Digitais. Marketing Digital. Meios de Hospedagem. Processo de Decisão de Compra online.

\section{$\underline{\text { Cite como }}$}

American Psychological Association (APA)

Barbosa, L. S. da S., Andrade-Matos, M. B. de., \& Perinotto, A. R. C. (2020). Marketing digital: a influência das mídias sociais digitais no processo de decisão de compra dos consumidores de meios de hospedagem. PODIUM Sport, Leisure and Tourism Review, São Paulo, 9(1), 154-170. https://doi.org/10.5585/podium.v9i1.14822. 


\title{
DIGITAL MARKETING: \\ THE INFLUENCE OF DIGITAL SOCIAL MEDIA ON THE PURCHASE DECISION PROCESS OF ACCOMODATION CONSUMERS
}

\begin{abstract}
Objective of the study: The present study aimed to analyze how accommodation consumers are influenced by digital social media in their purchase decision process.
\end{abstract}

Methodology / approach: The research was exploratory and quantitative, using data collection through online surveys applied in digital social media, with possible accommodation consumers. The survey consisted of multiple-choice questions and one discursive question. Data were analyzed using descriptive statistics and content analysis was used for the open question. Then a word cloud was constructed.

Originality / Relevance: With today's easy Internet access, consumers are taking more active roles in the purchase decision process, including its five steps: problem recognition, information seeking, alternative analysis, purchase decision, and finally, the post-purchase. Digital social media enable a multitude of possibilities for searching and accessing diverse information, which generates a new buying behavior for consumers, given the changes that are taking place in society.

Main results: According to the results, it was concluded that respondents are making frequent use of digital social media to conduct purchase research and exchange information with other consumers about lodging, so the experiences of others end up influencing the buying decision process of a person.

Theoretical / Methodological Contributions: To support the discussion, a literature review on digital marketing and digital social media, online consumer behavior, and the purchase decision process was developed. The most influenced stage by social media is the search for information, in which consumers seek references for their purchasing decisions. The most used social media for these users to get information are WhatsApp, Instagram, and Facebook, respectively.

Keywords: Digital Social Media. Digital marketing. Lodging. Online Purchase Decision Process.

\section{MARKETING DIGITAL: LA INFLUENCIA DE LOS MEDIOS SOCIALES DIGITALES EN EL PROCESO DECISORIO DE COMPRA DE MEDIOS DE ALOJAMIENTO POR PARTE DE LOS CONSUMIDORES}

\section{Resumén}

Objetivo de estudio: analizar cómo los consumidores de medios de alojamiento son influenciados por las redes sociales digitales en su proceso de decisión de compra.

Metodología / enfoque: La investigación es de tipo exploratoria y cuantitativa, utilizando la recopilación de datos, a través de cuestionarios aplicados online en las redes sociales 
digitales, con posibles consumidores de medios de alojamiento. El cuestionario incluía preguntas de opción múltiple y una pregunta abierta. Los datos se analizaron mediante estadísticas descriptivas y, para la cuestión abierta, se utilizó el análisis de contenido y, a seguir, se construyó una nube de palabras ("word cloud").

Originalidad / relevancia: con el fácil acceso actual a la Internet, los consumidores están adoptando roles más activos en el proceso decisorio de compra, incluidos sus cinco pasos: reconocimiento del problema, búsqueda de información, análisis de alternativas, decisión de compra y finalmente, la adquisición posterior. Las redes sociales digitales permiten una multitud de posibilidades para buscar y acceder a información diversa, lo que genera un nuevo tipo de comportamiento de compra en los consumidores, dados los cambios que están teniendo lugar en la sociedad.

Resultados principales: los resultados llevaron a la conclusión de que los encuestados están haciendo uso frecuente de las redes sociales digitales para realizar investigaciones e intercambiar información con otros consumidores, puesto que las experiencias de otros terminan influyendo, de alguna manera, en su proceso decisorio de compra.

Contribuciones teóricas y metodológicas: para apoyar la discusión, se desarrolló una revisión de la literatura sobre marketing digital, redes sociales digitales, comportamiento del consumidor online y proceso de decisión de compra. Sin embargo, es sabido que la etapa más influenciada por las redes sociales es la de búsqueda de información, en la cual los consumidores adquieren referencias para sus decisiones de compra. Las redes sociales más utilizadas por los usuarios para obtener información son WhatsApp, Instagram y Facebook.

Palabras clave: Redes sociales digitales. Marketing digital. Medios de alojamento. Proceso de decisión de compra online.

\section{Introdução}

Nos últimos anos, com o desenvolvimento tecnológico, a internet se tornou uma ferramenta de grande importância para os consumidores pois as organizações sentiram necessidade de se aperfeiçoarem e se adaptarem às mudanças que vêm ocorrendo no mundo virtual. Para Torres $(2009$, p.44) "a internet é uma rede de milhões de pessoas, de todas as classes sociais, que buscam informações, diversão e relacionamento e que comandam, interagem e interferem em toda e qualquer atividade ligada à sociedade e aos negócios".

De acordo com Garcia (2007), o marketing digital tem um relevante papel sobre o comportamento do consumidor. Sua definição é baseada na motivação do uso de mídias sociais, criando novos hábitos sobre o consumidor, tendo ainda a possibilidade de fazer pesquisas e buscar vantagens de acordo com seus desejos e necessidades, proporcionando através das mídias sociais uma maior eficiência nas campanhas de marketing. Com isso, o marketing digital incentivou um grupo de possibilidades, atuando como ferramentas de êxito dentro das empresas, como estratégia para facilitar a captação de novos clientes, a fidelização, e, assim, a garantia da decisão de compra (Vaz, 2010).

Com o avanço da internet, do marketing digital e das mídias sociais, as organizações mudaram a forma de se comunicar com seus consumidores. Dessa forma, o surgimento das 
mídias sociais ofereceu oportunidades de troca de informações entre pessoas de várias culturas e de buscar mais conhecimento sobre produtos e serviços com as empresas e com outros clientes, a qualquer hora e sem limites geográficos.

Acredita-se, assim, que as mídias sociais digitais têm influenciado o comportamento de compra online. Segundo Torres $(2009$, p.113) "as mídias sociais são sites na internet que permitem a criação e o compartilhamento de informações e conteúdos pelas pessoas e para as pessoas, nas quais os consumidores são ao mesmo tempo produtor e consumidor da informação". Cada vez mais usuários estão utilizando as mídias sociais como uma forma de expandir seus contatos, expor suas ideias e se relacionar com indivíduos de diversas regiões e localidades diferentes.

Decidir fazer compras pela internet também tem sido uma realidade frequente e que está ganhando espaço cada vez mais, trazendo benefícios aos consumidores, como comodidade, rapidez, variedade e agilidade, características que tem feito o mercado online crescer.

Mas para que a compra seja efetivada, seja ela online ou offline, há etapas que levam à decisão de compra. Segundo Mowen e Minor (2003) as etapas do processo de decisão de compra convencional são: reconhecimento do problema ou a tomada de consciência de uma necessidade; busca de informações; avaliação de alternativas; escolha ou decisão propriamente dita; e, por fim, a avaliação dos resultados.

Tais etapas perpassam o processo de decisão de compra de diversos tipos de bens e serviços, dentre ele o consumo de meios de hospedagem. Para Ribeiro (2011), os meios de hospedagem são grupos de empresas que oferecem acomodações em condições de segurança, higiene, respeito e satisfação aos clientes/consumidores que buscam por esses serviços. Diante da emersão das novas tecnologias e das novas formas de divulgação, os meios de hospedagem desenvolveram ações que resultaram em menores custos quando comparados às mídias tradicionais (televisão, revistas, jornais), conseguindo estar à disposição de consumidores a todo momento e possibilitando uma comunicação em tempo real, promovendo seus serviços e produtos como também sua marca.

Portanto, a decisão de pesquisar sobre a influência das mídias sociais digitais no processo de decisão de compra de meios de hospedagem se deu a fim de compreender a influência dessas mídias sobre os consumidores para que se conheça as implicações gerenciais, acadêmicas e sociais dessa realidade. Assim, o objetivo do estudo foi analisar como consumidores de meios de hospedagem são influenciados por mídias sociais no processo de decisão de compra. $O$ estudo foi realizado com consumidores de meios de hospedagem que utilizam as mídias sociais digitais.

Introduzido o objetivo deste estudo, a seguir serão apresentadas as bases conceituais nas quais a pesquisa se apoia, os seus procedimentos metodológicos, os resultados e, por fim, as considerações finais.

\section{Marketing Digital e Mídias Sociais}

A internet se tornou instrumento fundamental no ambiente organizacional, tanto para uso comercial quanto para o lazer, e, diante disso, o crescimento e a busca por sua utilização são significativos. Para Segura (2009), o marketing digital surgiu como um conjunto de ações para viabilizar de forma mais segmentada os meios de comunicação utilizados pelas organizações no ambiente online. Por meio da tecnologia, novas possibilidades para divulgar produtos e serviços surgiram, gerando capacidade para os empreendimentos conseguirem atrair mais consumidores, bem como crescer sua rede de relacionamento. Com o consumo 
pela internet em alta e as trocas de informações cada vez mais efetivas, se tornou mais simples a realização de pesquisas com a finalidade de melhorar serviços e produtos. A internet também permite uma maior visibilidade para as empresas, que tiveram que se tornar mais exigentes e cuidadosas com a sua imagem online e, assim, mais atualização e atenção são necessárias.

De acordo com Solomon (2011) este tipo de marketing tem uma capacidade maior de segmentação e uma comunicação distinta, tornando-se mais econômico em relação ao marketing convencional. É importante entender que o marketing digital se diferencia do marketing convencional, pois ele usa a internet como uma ferramenta para desenvolver relacionamentos com os clientes, de um jeito diferenciado e ao mesmo tempo individual de acordo com os desejos e necessidades de cada consumidor. Os consumidores têm a opção de buscar exatamente o que desejam, assim, conseguem de forma rápida executar e finalizar uma compra de acordo com sua vontade, com isso, a rapidez de uma comunicação entre a empresa e o possível cliente pode se transformar em um fator de alto valor para o sucesso.

Atualmente, outro fato que chama a atenção é o crescente uso das mídias sociais digitais, que são plataformas em que se constroem redes sociais online. Essas mídias se tornaram uma ferramenta em que o consumidor tem acesso rápido às informações positivas ou negativas sobre determinado produto ou serviço, através de opiniões de consumidores que já tiveram experiências vividas.

Relevante distinção a ser feita é que rede social difere de mídias sociais. Apesar do termo 'rede social' ser amplamente utilizado, parece inapropriado para as discussões que envolvem tais mídias. Coaduna-se com o que Wittell (2001) estabelece: a razão do uso indiscriminado do termo 'redes sociais' desenvolve-se a partir da transposição do termo das ciências sociais para uma visão tecnológica determinística a qual não está interessada em compreender as transformações das relações sociais. Prefere-se, portanto, identificar 'mídias sociais' como toda e qualquer plataforma digital que é utilizada para fins de comunicação e compartilhamento de informação a terceiros. Rede social, por consequência, representa o uso da mídia social que se dá pelo início e desenvolvimento de relacionamento entre pessoas e seus grupos de conhecidos e amigos, independente do meio que utilizam, quer seja este digital ou não. Deste esclarecimento, incorre em dizer que de uma mídia social pode se desenvolver uma rede social, mas nem toda rede social surge a partir de uma mídia social.

Para Kotler, (2009, p.13) "os computadores e a Internet causaram imensas mudanças comportamentais no processo de compra e venda". Diante disso, Castells (2001) nos coloca que "a Internet é um instrumento que desenvolve, mas que não muda os comportamentos; ao contrário, os comportamentos apropriam-se da Internet, amplificam-se e potencializam-se a partir do que são". As tecnologias midiáticas, por sua vez, deixam de ser observadas como suportes técnicos para a realização da comunicação e passam a ser observadas como mídias propriamente, sendo imprescindíveis para a realização de determinadas relações sociais. Com isso, parece ser cada vez mais tênue a diferença entre as relações que acontecem face a face e as relações mediadas por tecnologias midiáticas (Perinotto, 2013).

De acordo com uma reportagem da revista Exame (2014), não adianta apenas criar contas nas mídias sociais e mantê-las desatualizadas, essas plataformas são ferramentas de marketing que necessitam de acompanhamento diário, um planejamento para que sejam usadas de forma que venha fortalecer sua marca e não a prejudicar. Dessa maneira, é necessário um planejamento detalhado e estratégico para que os benefícios almejados sejam alcançados, evitando riscos desnecessários. Essas mídias sociais são aliadas importantes para as organizações e, para tanto, é preciso conhecer o valor e as características de cada uma delas individualmente. A comunicação de marketing está passando por uma revolução digital, com 
o crescente uso de mídias sociais (Hollensen, Kotler e Opresnik, 2017) em um cenário em que surgem oportunidades e ameaças. As instituições têm a possibilidade de trabalhar com estes instrumentos e, ao mesmo tempo, compartilham ambiente com a divulgação que é efetuada pelos próprios turistas nas mídias sociais. Tais comentários tendem a influenciar na decisão de compra de outros consumidores, pois são considerados mais confiáveis entre os usuários do que as mensagens comerciais (Buhalis e Law, 2008; Torres, 2009). No turismo, o conteúdo gerado pelo usuário tornou-se uma importante fonte de informação para os consumidores de viagens (Ayeh, Au e Law, 2013).

Para as organizações, é um desafio lidar com o fenômeno das mídias sociais pois é preciso que estejam atentas e acompanhem o que os consumidores publicam e compartilham, visto que este é um espaço de troca de informações entre o cliente e a empresa, conseguindo captar e despertar interesses de possíveis futuros clientes (Porto, 2014). As empresas conseguem, através da utilização das mídias sociais, algumas informações de grande valor para seus negócios, tais como: desejos e necessidades dos consumidores individuais, informações de seus concorrentes, trocas de informações, ideias e opiniões. Usando esses meios, as empresas podem crescer a preferência dos clientes pelos produtos e serviços, aumentar as vendas, a credibilidade e divulgar sua marca no mercado. As mídias sociais são uma ferramenta importante para o marketing digital, e ainda mais importante no Brasil, pois $80 \%$ dos brasileiros usam algum tipo de mídia social (Torres, 2009). online.

Na próxima seção serão tratados aspectos a respeito do comportamento do consumidor

\section{Comportamento do consumidor na era digital}

Um dos grandes desafios das organizações atualmente é entender o comportamento dos consumidores virtuais. As empresas procuram satisfazer as necessidades e desejos de um mercado-alvo, e aquelas que conseguirem entender o que influencia o processo de decisão de compra dos consumidores supostamente conseguirão vantagens sobre seus concorrentes.

Também, Farias, Costa e Perinotto (2017) compreendem que as empresas que apostam no potencial dos mercados virtuais hoje exibem os primeiros posts. Seria quase anacrônico pensar em um consumidor que sai de sua residência para uma agência de viagens, um meio de hospedagem, ou uma companhia aérea para comprar um produto turístico. Os tempos são outros. Com a visibilidade e flexibilidade possibilitadas pelas ferramentas da Web, turistas escolhem destinos, meios de hospedagem, companhias aéreas na tela de aparatos tecnológicos.

De acordo com Mowen e Minor (2003), o comportamento do consumidor é determinado como o estudo de unidades compradoras de processos de trocas envolvidos na compra, na despesa e na organização de mercadorias, serviços, experiências e ideias. Com isso, o consumidor se torna mais informado e mais exigente, voltado para o ambiente digital. O consumidor é influenciado por vários fatores através das mídias sociais digitais, os quais se referem aos fatos culturais, sociais e psicológicos. Esses elementos juntos se tornam necessários para delimitar o comportamento do consumidor e definir suas escolhas e desejos.

Solomon (2011) ressalta, ainda, que o consumidor evoluiu em relação às inovações e habilidades das tendências dos dias atuais. Desse modo, o autor considera que o estudo do comportamento do consumidor não deve estar limitado apenas ao momento da compra, deve ser considerado todo o processo, o que vem antes e o que vem depois da compra e as influências sofridas pelo consumidor nesses momentos.

Segundo Fuoco (2003, p.39), estar atento aos consumidores permite conhecê-los: 
Pela internet se chega a um tipo de cliente diferente daquele que a empresa já se acostumou a atingir pelos meios tradicionais. O importante para a organização é conhecer este novo consumidor. Ele deve ser estimulado a se apresentar e divulgar o mínimo de informações para que possa ser montado um perfil, saber valorizar cada detalhe informado pelo mesmo. A empresa deve estar atenta aos detalhes que irão trazer informações sobre sua personalidade, seus gostos e preferências. É importante identificá-lo a cada visita que ele faz ao site, ele saberá que os dados fornecidos não foram em vão e estão sendo usado para seu próprio benefício (Fuoco, 2003, P. 39).

Cabe ao marketing modificar as informações capturadas e transformar em dados de conhecimentos para poder usar em propagandas e, assim, induzir os consumidores a comprar cada vez mais seus serviços ou produtos de acordo com seus desejos e necessidades, podendo atingir a fidelização de clientes. Diante da possibilidade de poder ter uma comunicação maior, os consumidores começam a ter um papel fundamental, podendo compartilhar informações nas mídias sociais de acordo com suas experiências vividas, fazendo emergir conteúdos gerados pelo consumidor (UGC - user-generated content), relevante na gestão de mídias sociais na atualidade.

Na próxima sessão serão apresentados aspectos conceituais e teóricos do processo de decisão de compra online de meios de hospedagem.

\section{Processo de decisão de compra online de meios de hospedagem}

A compra de produtos e serviços pela internet tem tido um crescimento enorme, prática que vem ganhando cada dia mais adeptos, pois oferecem alguns benefícios como comodidade, rapidez, agilidade, além de ter diversas variedades apenas com alguns clicks. Devido a todos esses fatores, as empresas que se adaptaram a esse meio tecnológico estão conseguindo cada vez mais expandir seus negócios online.

Com um mercado em potencial, o Brasil já tem 116 milhões de usuários na internet, de acordo com uma pesquisa realizada pelo Instituto Brasileiro de Geografia e Estatística-IBGE (2018), exibindo aumento de mais de 7\% (sete por cento) no total de cidadãos online. De acordo com esses dados pode-se perceber um crescimento grande de pessoas usando a internet, tanto para relacionamentos pessoais como para fins organizacionais.

Um fator que se destaca nas decisões de compra online é a busca de informações e opiniões publicadas por outros consumidores sobre produtos e serviços. Quando essas informações e opiniões são colocadas nas mídias sociais, podem atingir um número grande de pessoas e, com isso, a empresa consegue divulgar sua marca - podendo esta projeção da marca ser positiva ou danosa para a sua imagem. Os conteúdos expostos nas mídias pelos consumidores podem ter influência nas decisões de terceiros. De acordo com Furlan e Marinho (2013, p. 9), "o ambiente on-line oferece grande ênfase nas opções de personalização, proporcionando atendimento exclusivo aos clientes com base em suas características e preferências". Muitos consumidores atualmente utilizam-se de mídias sociais para buscar mais informações sobre os serviços oferecidos pelas organizações, pois o ambiente online permite encontrar dados de forma mais rápida e precisa.

Antes de realizar uma compra, o consumidor passa por um processo de decisão. Compreender as etapas desse processo é valioso para que se compreenda as influências que levam à efetivação da compra. Para Mowen e Minor (2003), Solomon (2011) e Kotler e Keller (2006), o processo de decisão de compra é dividido em cinco etapas. Quais sejam: 
1. Reconhecimento do problema: o processo de compra começa quando o consumidor reconhece um problema ou uma necessidade. Essas necessidades podem ser criadas por incentivos internos (sede, fome) ou externos (propagandas visualizadas nas mídias sociais, por exemplo). Quando o marketing conhece os motivos que ocasionam essas necessidades nos consumidores, se torna mais simples desenvolver estratégias que provoquem interesse no cliente. Com a existência de um interesse (reconhecimento do problema), o consumidor passará para o segundo estágio. (Kotler \& Keller, 2006; Mowen \& Minor, 2003)

2. Busca de informações: o consumidor que tem uma necessidade, busca informações para conseguir supri-las. Esta etapa caracteriza-se como um processo de pesquisa por parte do consumidor com o propósito de encontrar informações que possam ajudar a solucionar o problema. A complexidade desta etapa dependerá do grau de envolvimento do consumidor. As fontes de informações do consumidor dividem-se em quatro partes, quais sejam: (a) Fontes pessoais - família, amigos, vizinhos, e conhecidos; (b) Fontes comerciais - propagandas, vendedores, representantes, embalagens, mostruários; (c) Fontes públicas - meios de comunicação de massa, organizações de classificação de consumo; e (d) Fontes experimentais - manuseio, exame, uso do produto. Quando essas informações conseguem convencer o consumidor, ele passará para a terceira etapa. (Kotler \& Keller, 2006; Solomon, 2011)

3. Avaliação das alternativas: nesta etapa o consumidor avalia as diversas alternativas identificadas no momento da buscar de informações para atender à sua necessidade, fazendo comparações entre elas e, assim, conseguir chegar à escolha de uma alternativa. As etapas de busca de informações e de avaliação das alternativas, mesmo sendo estudadas separadamente, ocorrem ao mesmo tempo durante o processo de decisão de compra. Ao buscar informação de um determinado produto, o consumidor já inicia o processo de avaliação que levará a pesquisar sobre outros produtos. (Mowen \& Minor, 2003; Kotler \& Keller, 2006)

4. Decisão de compra (escolha de uma alternativa): após o processo de avaliar as alternativas encontradas na busca, o consumidor escolhe apenas uma. Esta etapa passa por cinco subdecisões que são: (a) escolha por marca, (b) por revendedor, (c) por quantidade, (d) por ocasião e (e) por forma de pagamento. Logo após, definida sua escolha e efetuada a compra, o consumidor passará ainda por um último processo (Mowen \& Minor, 2003; Solomon, 2011), apresentado a seguir.

5. Avaliação pós-compra: nesta etapa o consumidor consome e utiliza o que foi adquirido podendo resultar em satisfeito ou não satisfeito. $O$ serviço do profissional de marketing não chega ao fim quando o produto/serviço é comprado, ele precisa permanecer monitorando a satisfação, as ações e a utilização em relação ao produto depois de ter feito a compra (Kotler \& Keller, 2006).

Apresentadas as discussões teóricas que baseiam a pesquisa, a seguir serão discutidos os procedimentos metodológicos utilizados.

\section{Metodologia}

O presente trabalho caracterizou-se como exploratório pois buscou o recolhimento de dados para analisar a influência das mídias sociais no processo de decisão de compra de consumidores de meios de hospedagem de maneira preliminar. Esse tipo de pesquisa busca 
conhecer com maior profundidade o assunto de modo a torná-lo mais claro ou levantar questões importantes para melhor conduzir a pesquisa. De acordo com Gil (2008), a pesquisa exploratória é desenvolvida de forma a proporcionar uma visão geral de um determinado fato. A pesquisa teve o objetivo de obter informações de consumidores, por meio de questionários aplicados online, para identificar a influência das mídias sociais sobre suas compras. Buscouse também conhecer quais mídias os consumidores mais avaliam para chegar em sua decisão de compra.

Devido às características da problemática estudada, foi realizada, como dito, uma coleta de dados através de questionários aplicados com consumidores de meios de hospedagem que possuem contas em mídias sociais. A utilização de questionários, para Andrade (2010), é uma técnica padronizada da coleta de dados que se caracteriza pela não interferência do pesquisador na coleta. Os questionários, elaborados e disponibilizados pelo Google Forms, foram compartilhados por meio de um link online na internet, enviados por meio das mídias sociais digitais dos autores (Facebook, WhatsApp e Instagram) e, na divulgação do instrumento de coleta de dados, foram convidadas a responder pessoas que já tivessem se hospedado em hotéis, tendo as reservas sido feitas online ou não. As respostas aos questionários produziram informações que foram tabuladas e interpretadas utilizando estatística descritiva.

Foram alcançados 150 respondentes/consumidores de meios de hospedagem. Para Gil (2008), uma amostra de 150 indivíduos é suficiente para uma população com amplitude infinita (maior que 100.000) de consumidores de meios de hospedagem com nível de confiança igual a $95 \%$, embora com um erro amostral de $10 \%$ para mais ou para menos. Os questionários foram respondidos entre o dia 28 de setembro e o dia 7 de outubro de 2018.

O instrumento de coleta de dados foi construído com quinze perguntas de múltipla escolha, elaboradas a partir do objetivo do estudo. Foi realizado um pré-teste do instrumento de coleta de dados com cinco alunos de graduação de uma instituição pública federal de ensino. Não foram feitos ajustes após o pré-teste e o tempo médio de resposta foi de 10 (dez) minutos.

Após o fim do período disponível do questionário, foi feita a análise dos dados a fim de quantificar e categorizar as respostas adquiridas na coleta. Segundo Andrade (2010), a análise estatística dos dados ocorre quando os fatos são registrados, analisados e interpretados, sem que o pesquisador interfira diretamente no processo, tendo, assim, uma menor subjetividade.

Para a única pergunta presente no questionário com opção de resposta aberta, ou seja, em que os pesquisados escreveram suas respostas de maneira espontânea, foram obtidas apenas 14 (quatorze) respostas. Os demais optaram por não responder à pergunta e deixaramna em branco. As respostas obtidas foram tratadas por meio de análise de conteúdo, que para Bardin (1977, p. 42) é:

Um conjunto de técnicas de análise das comunicações visando obter, por procedimentos sistemáticos e objetivos de descrição do conteúdo das mensagens, indicadores (quantitativos ou não) que permitam a inferência de conhecimentos relativos às condições de produção/ recepção (variáveis inferidas) destas mensagens.

Ainda para esta questão, foram criadas categorias e, depois, foi criado um "Word Cloud" com as respostas. O "word cloud" é uma ferramenta utilizada em que as palavras que têm maior incidência aparecem na imagem em tamanho maior e, do mesmo modo, as que foram citadas menos vezes aparecem em tamanho reduzido. Apresentados os procedimentos 
metodológicos e as técnicas de coleta e análise dos dados, a seguir serão discutidos os resultados.

\section{Resultados e discussão}

Nesta seção serão apresentados os resultados da pesquisa buscando atender os objetivos traçados e do instrumento de coleta de dados elaborado. A princípio, buscou-se conhecer o perfil dos sujeitos da pesquisa, consumidores de meios de hospedagem, com intuito de atender aos objetivos específicos do trabalho.

No que diz respeito à idade, o público respondente está majoritariamente inserido na faixa etária de até 25 anos, com 44\% dos respondentes. Seguindo, a faixa de 25 até 35 anos representou 39,9\% dos indivíduos pesquisados. Sendo assim, de maneira geral, os jovens e jovens adultos foram a grande parcela do público participante, o que pode ter sido influenciado pelo próprio meio no qual os questionários foram aplicados: as mídias sociais digitais.

Quando questionados sobre a sua escolaridade, 38,7\% respondeu ter curso superior completo e $34,7 \%$ superior incompleto. Isso demonstra que os respondentes têm uma formação superior em sua maioria.

De acordo com os dados adquiridos na pesquisa demonstra grande frequência do uso de mídias sociais entre os respondentes, já que 97,3\% afirmaram utilizar algum tipo de mídia social digital. Este dado corrobora com Torres (2009), que afirma que as pessoas estão fazendo uso dessas mídias sociais cada vez mais durante seu dia-a-dia.

Seguindo a sequência das questões, a próxima pergunta foi a respeito de quais mídias sociais são mais utilizadas no dia-a-dia dos pesquisados. De acordo com os dados adquiridos na pesquisa, é notório que o WhatsApp se sobressaiu diante das demais, chegando a atingir $92,7 \%$ dos participantes da pesquisa. A segunda que se destacou atingindo $73,3 \%$, foi o Instagram, seguido do Facebook com 56,7\%. Este dado corrobora com dados do IBGE (2018), que afirmam que a população está fazendo uso diário constante de algum tipo de mídia social, chegando a atingir 116 milhões de pessoas na internet. Tendo em vista este resultado, observa-se que o uso frequente e a grande exposição aos conteúdos gerados pelas mídias sociais, podem influenciar novos consumos, ou a exposição a conteúdos que antes não se havia contatos frequentes, como as experiências de viagens de outros viajantes. Isto pode, ou não, aumentar a frequência por busca de conteúdos de viagens e de hospedagem na internet. Nesse sentido, Filieri, Alguezau e McLeay (2015) afirmam que os consumidores/turistas/hóspedes coletam informações acerca das percepções das experiências de outros turistas-consumidores para planejar efetivamente sua viagem

Quando questionados sobre o hábito de fazerem reservas de meios de hospedagem online, $55,3 \%$ dos pesquisados responderam que não realizam e 44,7\% responderam que sim. Assim, apesar de não grande, ainda há uma maioria de respondentes desta pesquisa que fazem suas reservas em hotéis fora do ambiente online.

Outra questão buscou conhecer o hábito de realização de busca de informações, especificamente sobre se consumidores pesquisam no - ambiente online - a respeito de meios de hospedagem onde possivelmente se acomodarão. A maioria dos respondentes afirmou $(63,3 \%)$ que faz pesquisas no ambiente online, especificamente nas mídias sociais. $22 \%$ dos pesquisados afirmaram que não realizam pesquisas online, por fim, 14,7\% dos respondentes afirmaram que buscam informações sobre meios de hospedagem online às vezes. Estes dados demonstram que a etapa de busca de informações, conforme tratam os autores Mowen e Minor (2003) e Solomon (2011), tem sofrido influência da internet e de mídias sociais 
digitais, já que uma parte significativa de consumidores relatou informar-se online sobre os meios de hospedagem. Chama a atenção neste resultado o fato de um percentual maior de consumidores realizarem a etapa de busca por informações online, mas nem todos efetivamente relatarem fazerem as reservas online. Estes dados podem representar o número de consumidores que ainda não se sente à vontade para realizar compras online, por motivos de segurança, por exemplo, mas que a utilizam para buscar informações.

Seguindo os relatos dos resultados, na Figura 1 a seguir ficam visíveis alguns motivos pelos quais os respondentes fazem reservas online. Os respondentes, nesta questão, poderiam escolher mais de uma opção e selecionar as que se identificassem, sem limites. Nas respostas, o que mais ficou em evidência foi a comodidade que as mídias sociais trazem aos consumidores chegando a $48,8 \%$, seguido de $44 \%$ que o fazem devido aos preços baixos. Para Furlan e Marinho (2013), as mídias sociais trazem facilidade para os consumidores, pois o ambiente online é mais ágil e preciso por conter tudo que precisa em apenas alguns clicks sem que o usuário precise sair de casa. Os dados desta pesquisa também demonstram alguns fatores que contribuem para a comodidade do consumidor, corroborando com os autores.

Figura 1 - Motivos que mais contribuem pra realização de reservas online

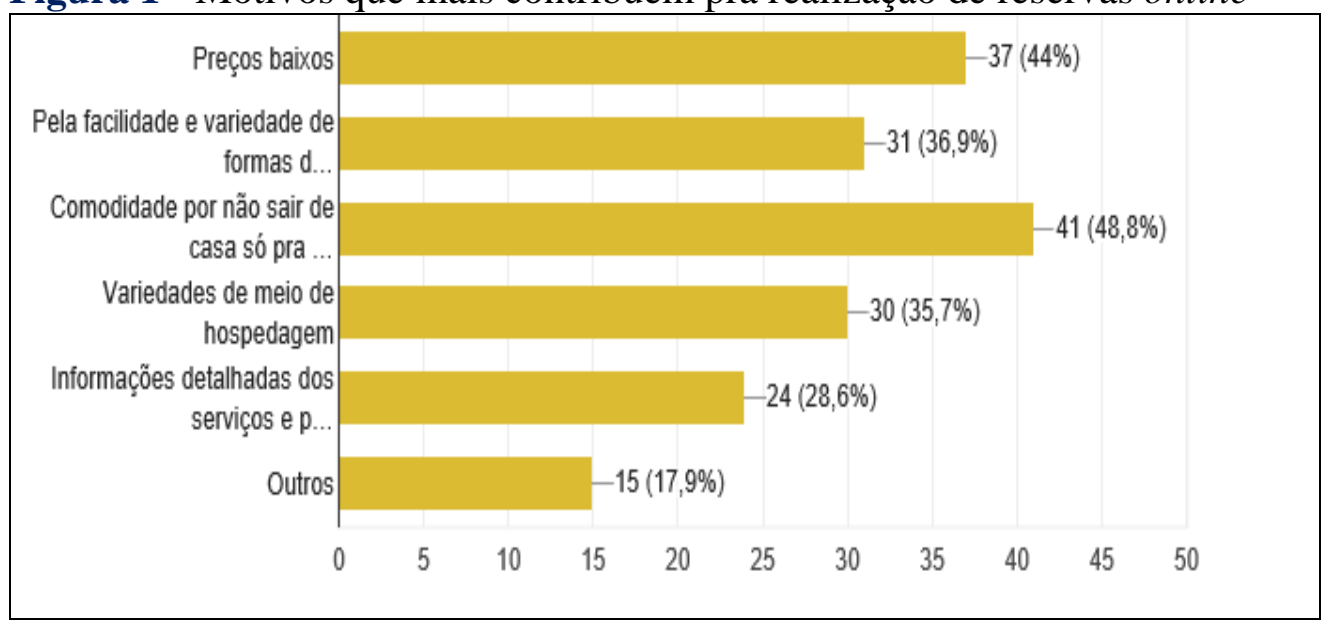

Fonte: Dados da pesquisa (2018).

Já quando perguntados sobre se já haviam deixado de realizar uma reserva de meio de hospedagem por terem lido algo a respeito do empreendimento e dos serviços prestados nas mídias sociais, a maioria das respostas adquiridas, $62 \%$, relataram que já deixaram de fazer uma reserva.

Durante a pesquisa também foi questionado aos pesquisados sobre fazer reclamações nas mídias sociais dos produtos e serviços mal prestados pelos meios de hospedagem, e a maioria dos respondentes respondeu que sim, com 54,7\%. Com isso, foi perguntado se a empresa conseguiu resolver o problema relatado, 38,5\% dos respondentes afirmaram que as empresas não resolveram, 36,5\% responderam que resolveram às vezes, e, por fim, 25\% responderam que as empresas conseguiram resolver esses problemas. Esses dados demonstram que a internet é utilizada para o que Kotler e Keller (2006) chamam de $5^{\mathrm{a}}$ (quinta) etapa do processo de compra, a avaliação pós-compra, na qual os consumidores fazem uso dos serviços e produtos e avaliam os resultados que podem ser positivos ou negativos.

Conforme os dados apresentados na Figura 2, as pessoas estão cada vez mais passando seu tempo nas mídias sociais, interagindo com outras pessoas, pesquisando ou trabalhando. Como pode ser observado, 32\% respondentes estão passando mais de 5 (cinco) horas 
acessando as mídias sociais, e $24,7 \%$ dos pesquisados usam mídias sociais digitais por mais de 2(duas) horas. Corroborando com Menegatti et al (2017) que afirmam que os brasileiros também ficam, em média, cinco horas por dia online, e $92 \%$ deles também participam de alguma mídia social.

Figura 2 - Tempo acessando as mídias sociais por dia

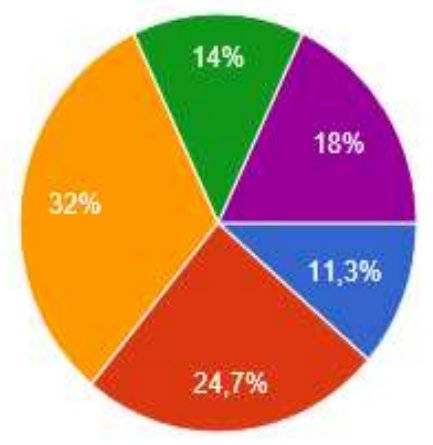

Até uma Hora

Até duas Horas

Até cinco Horas

Até oito Horas

Mais de oito Horas

Fonte: Dados da pesquisa (2018).

Entre os sujeitos pesquisados sobre a questão de qual é a vantagem de se ter um perfil nas mídias sociais, na qual os respondentes poderiam escolher várias opções, $78 \%$ afirmou que um dos benefícios é o acompanhamento das notícias, e $76 \%$ as trocas de informações com outros. Isso mostra que os respondentes estão buscando acompanhar cada vez mais as notícias que são divulgadas nas mídias sociais e, além disso, conectarem-se com outras pessoas. Desse modo concordando com o proposto por Araújo e Zilber (2016), em que afirmam que a mídia social é um grupo de aplicações fundamentadas na internet que constituíram na construção sobre os alicerces ideológicos e tecnológicos da Web 2.0 e 3.0, as quais consentem a criação e a permuta de conteúdo gerado pelo usuário (user-generated contents - UGC). Os indivíduos arranjam uso do UGC de costumes diferentes para distintas finalidades, como por exemplo, para obter informações, para o entretenimento, para interação com o conteúdo da Web e com outros seres humanos e para produzir seus próprios conteúdos em sites gerados pelo usuário.

Figura 3 - Vantagens de se ter um perfil nas mídias sociais

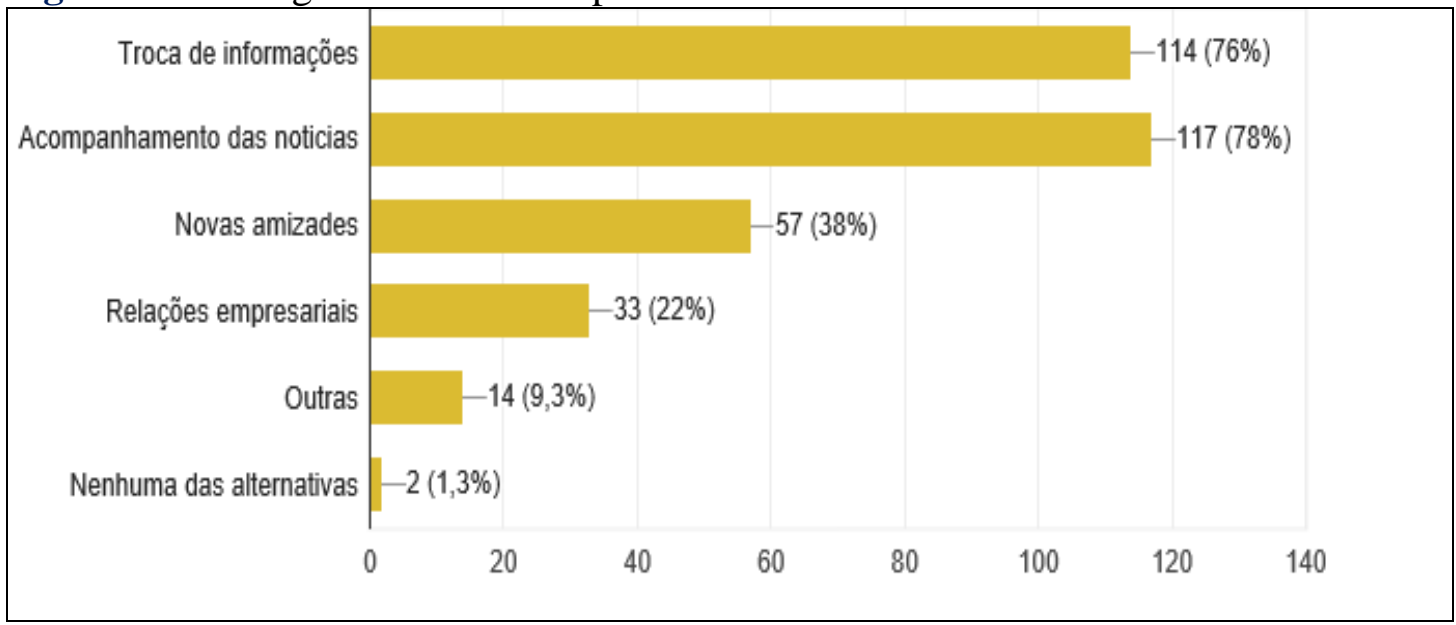

Fonte: Dados da pesquisa (2018).

Quando questionados sobre como se sentem com relação à influência das mídias sociais sobre suas escolhas e decisões, houve predominância da resposta 'sim' com 90\% de 
respondentes, como pode ser visto no gráfico (Figura 4). Isso reforça como as buscas sobre o que está sendo falado nas mídias sociais sobre os meios de hospedagem podem interferir na decisão de compra das pessoas, e que, ainda, as pessoas reconhecem esta influência. Esses dados corroboram com o que foi apresentado pelos autores Andrade, Mota, Ferreira e Perinotto (2018, p. 35) quando afirmam que:

A experiência turística vivenciada pelo seguidor de perfis sociais de influenciadores digitais baseia-se na motivação, necessidades e desejos criados com a busca de informações através da Internet. Tais fatores estão diretamente ligados ao poder de influência que esses profissionais têm de alavancar a promoção de um destino turístico, por meio do marketing boca a boca feito a partir de suas redes sociais. Cada experiência é única, e essa, quando positiva, não apenas desperta anseios, mas também promove confiabilidade em quem compartilha a vivência experimentada durante uma viagem.

Figura 4 - Influência de mídias sociais sobre decisões de compra de meios de hospedagem

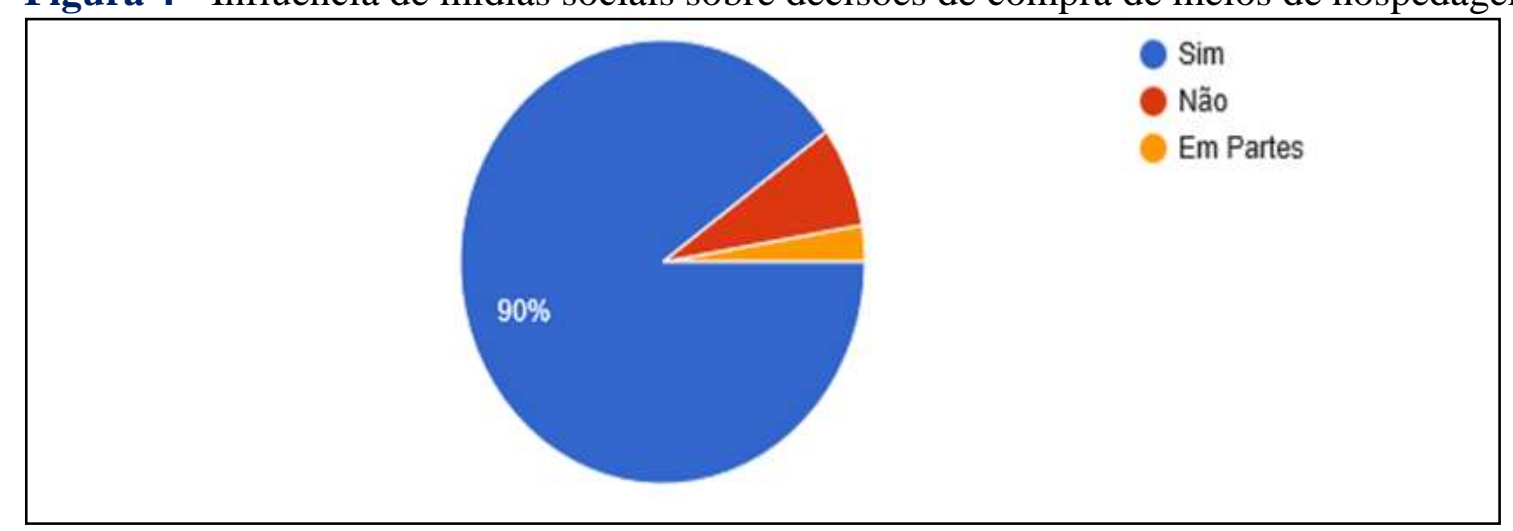

Fonte: Dados da pesquisa (2018).

Para os sujeitos que responderam "em partes", abriu-se a possibilidade para a resposta aberta, com o espaço de resposta livre (a única desse tipo, que obteve quatorze respostas, como apresentado na metodologia). A partir das respostas dadas a esta questão foi possível compreender que os respondentes acreditam que podem ser influenciadas pelas atuais mídias sociais, já que elas estão absorvendo várias opiniões e interagindo com esses indivíduos. Mostrando, na prática, que o ambiente online pode sim influenciá-los, corroborando com Andrade, Mota, Ferreira e Perinotto (2018), pois as redes sociais digitais são instrumentos de influência digital para a promoção de destinos e de serviços turísticos, e esta é uma realidade com marketing dirigido, ou mesmo, de forma involuntária, pois a internet abriu oportunidades para espalhar as informação e criar interação entre usuários.

Buhalis e Law (2008) afirmam que o uso das tecnologias admite que as instituições de turismo desenvolvam abordagens de marketing para distintos mercados-alvo acolhendo a satisfação de cada mercado, de forma mais personalizada. Desse modo, a internet permite, também, a justaposição e descoberta de novas experiências, estimulando e permitindo viabilidade do consumo em turismo.

Com as respostas obtidas através desta questão, foi realizada uma análise de conteúdo e, após análise, foi criado um "Word Cloud” que pode ser observada na Figura 5, a seguir: 
Figura 5 - Resultado da Análise de Conteúdo feita na questão aberta, respondida pelos sujeitos que afirmaram que são influenciados "em partes" pelas mídias sociais nas decisões de compra

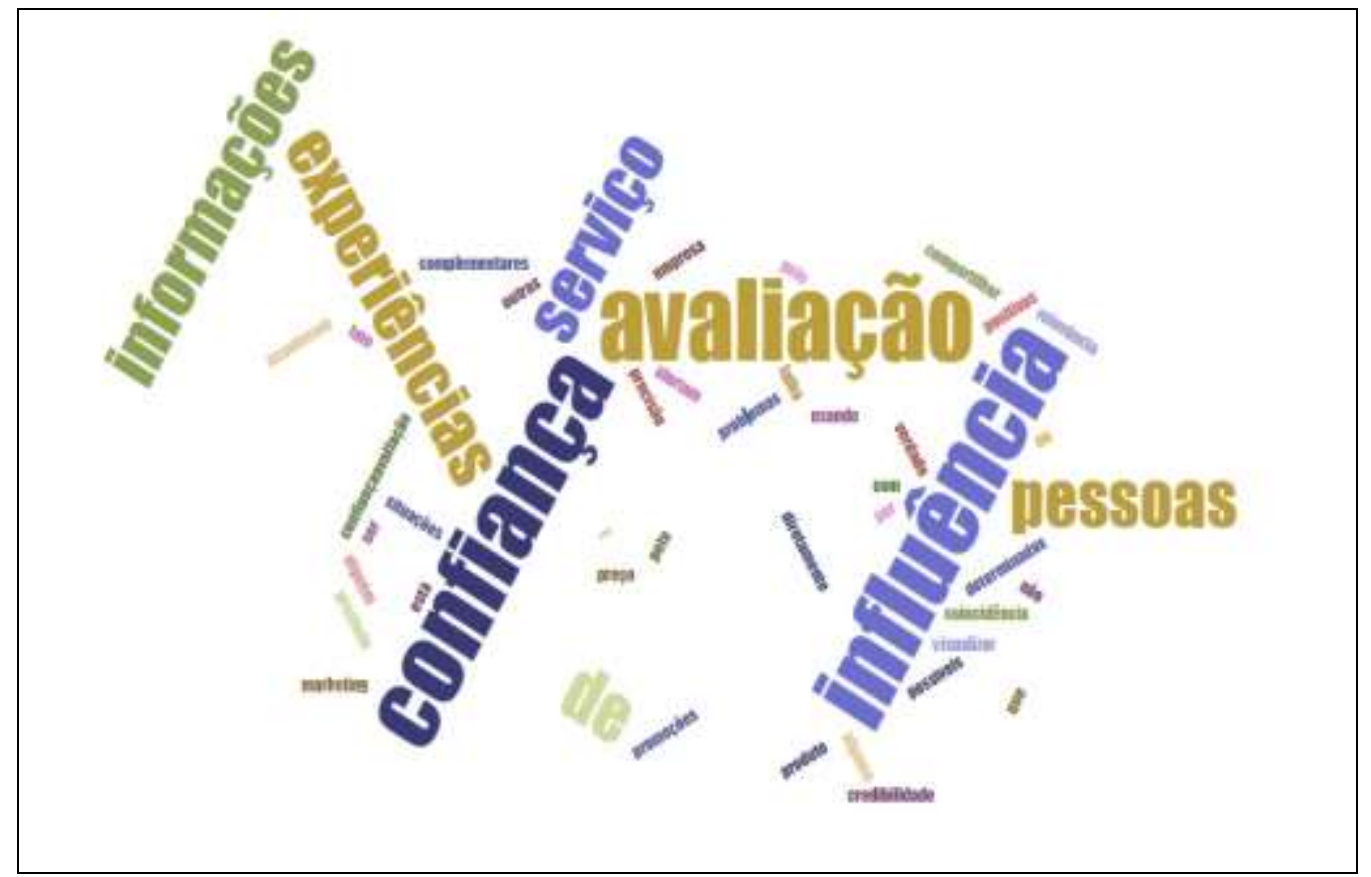

Fonte: Dados da pesquisa (2018)

A construção do Word Cloud, nuvem de palavras, foi feita por meio do Website gratuito wordclouds.com, o qual segue padrões em que palavras maiores são mais significativas que as palavras menores. As cores das palavras não possuem significado específico. Os conteúdos que se destacam entre as respostas são: informações, experiências, influência, avaliação, confiança, serviço e pessoas. Desse modo, a influência digital acaba se tornando uma forma de confiabilidade pela experiência de outro consumidor, podendo ser utilizada como uma ferramenta de marketing digital na propagação de novas marcas e/ou produtos, bem como serviços e lugares. Desse modo, corroborando com Farias, Costa e Perinotto (2017) que comentam que empresas de turismo são fortemente impactadas, como a credibilidade da opinião surge não só da publicidade oficial, mas dos comentários de amigos, familiares e usuários online, que passaram pelas mesmas experiências, facilidades e dificuldades. Essa opinião do usuário de redes sociais digitais é exposta a todos na rede, incluindo suas imagens fotográficas postadas. Símbolos do turismo internacional, por exemplo, podem ser mencionados como 'representantes' da tendência para mediar experiências de turismo via Web, como estão disponíveis em plataformas $W e b$ e em aplicações para sistemas IOS-Apple e feedback do Android-Google com clientes / convidados para facilitar o acesso a informações e desenvolver a cultura de exposição de superexposição.

Os mercados de turismo são exemplos básicos da flexibilidade da demanda, o resultado imediato dessa nova realidade é a maior participação de turista/consumidor nas configurações dos produtos. Nesse sentido, o consumo do modelo fordista-rígido expira na Web 2.0, e ainda na Web 3.0 há uma mudança de atitude. Não seria de outro modo, para afirmar que a maneira essencial de assimilar esta flexibilidade/adaptabilidade da demanda é o entendimento dessa infraestrutura tecnológica no dia-a-dia dos potenciais consumidores. Plataformas de redes sociais digitais (mídias sociais), entre outros, verificam essa realidade. 
Assim, muitas empresas poderiam fazer uso da confiabilidade e poder de propagação que os usuários de redes sociais digitais possuem com seus comentários e avaliações.

\section{Conclusão}

Para a realização desta pesquisa, que teve como objetivo analisar a influência das mídias sociais no processo de decisão de compra dos consumidores de meios de hospedagem, foi desenvolvida uma coleta de dados por meio de questionários aplicados online com consumidores de meios de hospedagem. Nos resultados, foi possível constatar a importância que essas mídias estão tendo sobre os consumidores.

As mídias sociais estão se transformando em uma importante ferramenta de comunicação para os meios de hospedagem, uma vez que proporcionam o diálogo com um grande público em tempo real. Permitem, assim, a possibilidade de conexão com diversas pessoas, diversos perfis, faixas etárias diferentes e chamar atenção não apenas das pessoas como também das organizações.

Os meios de hospedagem, percebendo esta grande influência das mídias sociais nos consumidores, estão buscando fazer uso destas ferramentas para divulgar sua marca, produtos e serviços, criando uma aproximação maior com seus consumidores.

O objetivo central deste trabalho foi analisar como consumidores de meios de hospedagem são influenciados por mídias sociais no processo de decisão de compra. Ao analisar as respostas dos sujeitos, constatou-se que o uso das mídias sociais é frequente no dia-a-dia dos respondentes, sendo o WhatsApp a rede mais utilizada pelos sujeitos pesquisados por disponibilizar maiores rapidez e facilidade. A segunda mídia mais usada é o Instagram e a terceira o Facebook. Os meios de hospedagem, por sua vez, estão percebendo que podem fazer bom uso dessas mídias para divulgar vídeos, fotos, informações, programações e até promoções para seus clientes. Por isso, muitos mantém as mídias atualizadas diariamente para melhor atender os seus consumidores.

Constatou-se nesta pesquisa, ainda, que as mídias sociais são relevantes no processo de decisão de compra dos consumidores, pois esses estão cada vez mais inseridos nas redes sociais digitais, buscando informações tanto dos próprios meios de hospedagem, como das pessoas que já tiveram alguma experiência nele.

Ao analisar as 5 (cinco) etapas do processo de decisão de compra - ou seja, o reconhecimento do problema, a busca de informações, a avaliação das alternativas, decisão de compra e avaliação pós-compra - foi possível perceber que a mais influenciada pelas mídias sociais é a busca por informações. Isso ocorre já que os consumidores fazem uso dessa ferramenta para conseguir notícias sobre algum tipo de produto ou serviço. A etapa de decisão de compra em si, é a segunda mais influenciada. Isso ficou visível já que os respondentes demonstraram sofrer influência das mídias sociais através das pessoas e também das organizações. Por fim, a etapa de avaliação pós-compra também é influenciada, já que os consumidores podem relatar suas experiências para outras pessoas e, através disso, também influenciam terceiros com suas experiências vividas.

As empresas turísticas e também os destinos turísticos são impactados pelos conteúdos gerados nas mídias sociais, pois a credibilidade origina da opinião de amigos, familiares e outras pessoas, que passaram pelas experiências turísticas e por certas dificuldades. Assim, essa opinião do usuário nas mídias sociais está exposta para todos na rede, seus conteúdos gerados (vídeos, fotos, textos, dentre outros) certamente, como visto nas palavras no "world cloud", criam credibilidade e confiabilidade para compras, podendo ser utilizados como estratégia de marketing digital pelos meios de hospedagem. 
Sugere-se, assim, com esta pesquisa, que os sujeitos respondentes utilizam as mídias sociais frequentemente, principalmente WhatsApp, Instagram e Facebook, para obter informações de produtos e serviços dos meios de hospedagem. Ficou também aparente que as mídias sociais se tornaram uma ferramenta de comunicação importante para os meios de hospedagem, pois é onde os clientes se encontram, discutem e demonstram suas opiniões a respeito de tudo, principalmente de suas experiências com a empresa e os produtos oferecidos.

Durante o desenvolvimento deste trabalho, algumas limitações foram percebidas quanto à sua amostra, visto que o questionário não passou muito tempo disponível por limitação de tempo, o que aumentou a margem de erro do estudo. Para futuras pesquisas, sugere-se que se realize um estudo com alguns meios de hospedagem para verificar a importância das mídias sociais, utilizando métodos qualitativos para que se tenha um maior detalhamento e aprofundamento do ponto de vista do negócio.

\section{Referências}

Andrade, B. L. S.; Mota, D.; Ferreira, H. P.; Perinotto, A. R. C. (2018). As mídias sociais e os influenciadores digitais na promoção de destinos turísticos. Revista Anais Brasileiros de Estudos Turismo/ABET, Juiz de Fora, v.8, n.2, pp.32 - 42, Maio/Ago.

Andrade, M. M. (2010). Introdução à metodologia do trabalho cientifica: Elaboração de trabalhos de graduação. 10. Ed. SP: Atlas.

Araújo, J. B.; Zilber, S. N. (2016). Que Fatores Levam as Empresas a Adotar Mídias Sociais em seus Processos: Proposta e Teste de um Modelo de Medição. Brazilian Business Review, Vol. 13(6), (Nov/Dec 2016): 270-303.

Ayeh, J. K., Au, N. \& Law, R. (2013). Do We Believe in TripAdvisor? Examining Credibility Perceptions and Online Travelers' Attitude toward Using User-Generated Content. Journal of Travel Research, 52(4), 437-452.

Bardin, L. (1977). Análise de conteúdo. Lisboa: Edições 70.

Buhalis, D.; Law, R. (2008). Progress in information technology and tourism management: 20 years on and 10 years after the Internet-The state of eTourism research. Tourism Management, 29(4), 609-623.

Castells, M. (2001). Internet e sociedade em rede. In: Bauman, Z. Modernidade líquida. Rio de Janeiro: Jorge Zahar Editor.

Demartini, F. (2018). O Brasil tem 116 milhões de usuários na internet. $<$ https://canaltech.com.br/internet/brasil-tem-116-milhoes-de-usuarios-de-internet-afirmaibge-108612/>. Acesso em: 16 de agosto de 2018.

Exame (2014). Kotler diz o que faria se estivesse começando hoje. Revista Exame. Disponível em: <https://exame.abril.com.br/revista-exame/kotler-porkotler> Acesso em: 08 de agosto de 2018.

Farias T. R. P.; Costa, J. H.; Perinotto, A. R. C. (2017). Empresas turísticas, redes sociales y negocios electrónicos. Estudios y Perspectivas en Turismo. V. 26 (2017) pp. 626 - 643.

Filieri, R.; Alguezaui, S.; McLeay, F. (2015). Why do travelers trust TripAdvisor? Antecedents of trust towards consumer-generated media and its influence on recommendation adoption and word of mouth. Tourism Management, 51, 174-185.

Fuoco, T. (2003). Guia do Valor econômico de comércio eletrônico. São Paulo: O Globo.

Furlan, B. E.; Marinho, B. (2013) Redes sociais Corporativas. Instituto Desenvolve TI: cursos para capacitação digital. Disponível em: $<$ https://jornaldoempreendedor.com.br/empreendedorismo-na-Web/novidades-pela- 
net/redes-sociais-corporativas-novo-e-book-gratuito-para-download/> Acesso em: 29 de agosto de 2018.

Garcia, G. M. (2007). Comportamento do consumidor virtual: a influência das características pessoais na intenção de compra. Tese (Pós-Graduação) - Universidade Federal do Rio Grande do Sul.

Gil, A. C. (2008). Como elaborar projetos de pesquisa. 4 ed. São Paulo: Atlas.

Hollensen, S.; Kotler, P.; Opresnik, M. O. (2017). Social Media Marketing: A Practitioner Guide. Opresnik Management Consulting, 2017.

Kotler, Philip (2009). Marketing para o século XXI: como criar, conquistar e dominar mercados. São Paulo: Editora.

Menegatti, Maicon Souza; Ribeiro, Ivano; Meneghatti, Marcelo Roger; Serra, Fernando Antonio Ribeiro. (2017). Decisão de Compras Pela Internet: Uma Análise a Partir do Tempo de Utilização de Mídias Sociais e da Interatividade com a Marca. Brazilian Journal of Marketing - BJM Revista Brasileira de Marketing - ReMark Vol. 16, N. 1. Janeiro/Março. 2017

Mowen, J. C.; Minor, Michael. S (2003). Comportamento do consumidor.1. Ed. São Paulo: Pearson Prentice Hall.

Perinotto, A. R. C. (2013). Circulação de imagens turísticas : fotografias de Parnaíba/PI nas mídias / por André Riani Costa Perinotto. Tese (doutorado) - Universidade do Vale do Rio dos Sinos, Programa de Pós-Graduação em Ciências da Comunicação.

Porto, C. (2014). Facebook Marketing. São Paulo: Novatec.

Ribeiro, K. C. C. (2018). Meios de hospedagem: Centro de Educação Tecnológica do Amazonas. 2011. Disponível em: <http://redeetec.mec.gov.br/images/stories/pdf/eixo_hosp_lazer/061112_meios_hosp.pdf > Acesso em: 29 de agosto de 2018.

Segura, M. C. (2009). O estudo do Marketing Digital versus Marketing Tradicional e a percepção das suas campanhas por parte dos consumidores no mercado virtual a tradicional. 2009. f. 51. Dissertação (Mestrado em estatística e Gestão da Informação) Instituto Superior de Estatística e Gestão de Informação da Universidade Nova de Lisboa, Lisboa.

Somolon, M. R. (2011). O comportamento do consumidor: comprando, possuindo e sendo. 9. ed. Porto Alegre, RS: Bookman.

Torres, C. (2009). A bíblia do marketing digital. $1^{a}$ edição. São Paulo: Novatec.

Vaz, C. A. (2010). Google marketing: o guia definitivo de marketing digital.3. ed. São Paulo, SP: Novatec Editora.

Wittel, A. (2001). Toward a network sociality. Theory Culture Society. Vol.18 (6), pp. 51-76. 